\title{
Article
}

\section{Recognition, inclusion and democracy: learning from action research with young people}

Percy-Smith, Barry, McMahon, Gráinne and Thomas, Nigel Patrick Available at http://clok.uclan.ac.uk/25972/

Percy-Smith, Barry, McMahon, Gráinne and Thomas, Nigel Patrick ORCID: 0000-0002-5310-9144 (2019) Recognition, inclusion and democracy: learning from action research with young people. Educational Action Research, 27 . pp. 347-361. ISSN 0965-0792

It is advisable to refer to the publisher's version if you intend to cite from the work. http://dx.doi.org/10.1080/09650792.2019.1577149

For more information about UCLan's research in this area go to http://www.uclan.ac.uk/researchgroups/ and search for <name of research Group>.

For information about Research generally at UCLan please go to http://www.uclan.ac.uk/research/

All outputs in CLoK are protected by Intellectual Property Rights law, including Copyright law. Copyright, IPR and Moral Rights for the works on this site are retained by the individual authors and/or other copyright owners. Terms and conditions for use of this material are defined in the policies page.

\section{CLoK}

Central Lancashire online Knowledge www.clok.uclan.ac.uk

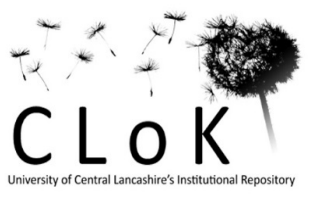




\title{
Recognition, inclusion and democracy: learning from action research with young people
}

\author{
Barry Percy-Smith ${ }^{a}$, Gráinne McMahon ${ }^{b}$ and Nigel Thomas ${ }^{c}$ \\ ${ }^{a}$ Centre for Applied Childhood, Youth and Family Research, University of Huddersfield, Huddersfield, UK; \\ ${ }^{\mathrm{b}}$ Centre for Citizenship, Conflict, Identity and Diversity, University of Huddersfield, Huddersfield, UK; \\ ${ }^{c}$ Centre for Children and Young People's Participation, University of Central Lancashire, Preston, UK
}

\section{ABSTRACT}

This paper draws upon learning from three action research projects conducted as part of a Europewide project exploring young people's social and political participation. Challenging dominant discourses about what 'counts' as participation and what does not, the paper explores how, through the action research projects, young people engaged in knowledge democracy in 'new democratic arenas'. Building upon experiential knowing and creating knowledge and learning through practice, the young people explored their own democratic knowledge production, communication and engagement within a context of shifting discourses of participation, democratic engagement and active citizenship. The increasing preference of young people for more informal forms of participation as lived practice reflects a shift to young people constructing their own modes of participation and 'remaking democracy' in their own vision and according to their own needs. By working outside of the confines of normative assumptions of democratic practice and participation, young people exercised their own 'political' agency in response to their own priorities, interests and concerns and, in doing so, illustrated that new forms, understandings and practices of knowledge democracy can emerge that reflect the promise of inclusive democratic societies more meaningfully.

\section{KEYWORDS}

Youth participation; political participation; action research; citizenship; youth activism; knowledge democracy

\section{Introduction: young people's participation and knowledge democracy}

There is concern across Europe about the extent to which young people participate in society (Walther 2018). Prevailing discourses of youth participation tend to emphasise young people's participation in formal decision-making processes over other forms of political participation (Thomas 2007; Percy-Smith 2018; Henn and Foard 2012). There is, however, a developing critique that these 'mainstream' discourses of youth participation are driven by adult concerns that pedagogise youth participation as a means of promoting 'active citizenship' and that such approaches often fall short of meaningful engagement for young people themselves (Pickard and Bessant 2018). Indeed, there is growing evidence that many young people want to be(come) politically and socially engaged but that mainstream structures for participation are increasingly becoming unattractive to them (Henn and Foard 2012). Adult-led agendas and structures tend to prioritise adult knowledge over young people's values, agendas and priorities, and exert a control on forms and styles of democratic engagement (Rainsford 2014a). 
There are two interpretations of 'knowledge democracy' here. The first concerns the different forms of knowledge that are acknowledged and respected as legitimate expressions of democratic participation. Within this formulation, (young) people's parti-cipation is significant as an expression of democratic rights of citizenship in terms of the contribution and inclusion of different knowledge and perspectives in society - as Young (2000) observes, 'social difference as a political resource'. The second interpreta-tion focuses on the ways in which different forms of knowledge and knowledge production are actively mobilised as a political force within a democratic society.

There is a dialectic at play in these interpretations, however, in that insufficient power and access to shape the structures of democratic participation compromises inclusion and influence. The dominance of particular democratic structures and processes that privilege some groups over others (such as adults over young people) is itself undemo-cratic and reflective of wider structural inequalities (Phillips 1993). To that extent, the context of differential access to power and influence is crucial for interpreting knowl-edge production, and connections between inclusion and participation are important. Including marginalised groups (such as young people) in decisionmaking is central; however, inclusion also concerns the extent to which such groups are able to play an equal and active role in contributing to everyday life (Percy-Smith 2018; Young 2000). Interpretations of inclusion and citizenship in terms of rights, and entitlement to and use of space, provide alternative frames of reference for understanding patterns of partici-pation and the representation of interests in broader terms. This is especially so for young people's interests and values, which are often marginalised across urban land-scapes and social institutions. Where that is the case, marginalised groups often try to create their own forms of democratic participation beyond the walls of the establishment (Walther 2018). Young people's engagement on their own terms and in alternative ways is not necessarily new; nonetheless, dominant discourses of what 'counts' as participation still fail to recognise it (Henn and Foard 2012; Pickard and Bessant 2018).

Within this context, knowledge democracy, played out through participation, is a process of communicative action that itself widens the understanding of the concept of participation beyond conventional decision-making contexts to encompass wider notions of social and civic participation (Percy-Smith 2018). Gaventa (2004) highlights the growing recognition of the 'importance of local knowledge and understanding as a basis for local action, and on direct forms of participation' (28).

Within, and perhaps because of, these changing contexts of participation, there has been increasing attention directed to the broadening and deepening of democracy in what Cornwall and Coelho (2007) refer to as 'new democratic arenas' involving alternative forms of democratic engagement. On one hand, these developments might signal a resurgence of 'people's participation' (Fals-Borda 1998) as young people show a preference for self-initiated action rather than for engaging with adult/ professional driven agendas. Equally, however, these changes could imply a further disenfranchisement of young people from wider society and the democratic process as they navigate the 'margins of citizenship' (McMahon et al. 2018). Either way, these developments signal a maturing of democracy as anachronistic structures and practices are challenged by new and innovative forms of democracy that are characterised by grassroots, creative and participatory forms, socio-cultural styles, and the political rather than politics per se (Walther 2018), that challenge assumptions about whose knowledge counts (Hickey and Mohan 2004).

\section{Young people's knowledge and democracy}

Though young people are central to many of these new developments in citizen participation, they remain maligned and often assumed to lack an interest or ability to engage in democratic processes (Walther 2018). Young people's knowledge and actions as citizens are marginalised, if they are recognised at all; their knowledge is not valued in its own right, but only in relation to a greater wisdom of adults, mediated through intergenerational power differentials (Rainsford 2014b). 
Whilst a minority of young people may continue to participate in formalised settings framed by adult agendas from which they derive some benefit, many participate in worlds apart from adults (Matthews, Limb, and Percy-Smith 1998) giving rise to parallel democracies. Young $(2000,13)$ importantly notes that 'if inclusion in decision-making is a core of the democratic ideal, then, to the extent that such political exclusions exist, democratic societies do not live up to their promise'. She also argues that the 'democratic process cannot be centred in particular places, but rather concerns the communicative relation of broad social sectors in the public spheres of civil society' (10). Further, as Fielding and Moss $(2011,42)$ contend: ' . . . modern democracies must also be "everyday democracies", with participatory democracy present and practised in many settings and in many ways'. These arguments suggest that a 'commitment to cultural autonomy and the selfdetermination of peoples' (Young 2000, 9) is central to knowledge democracy.

There is growing evidence that young people are participating in, and with respect to, their own forms of knowledge production and democratic processes within their everyday lives (McMahon et al. 2018; Walther 2018). The emerging focus on the participation of young people in everyday, often informal, contexts as 'lived practice' (Lister 2008) is matched by a growing appreciation that participation involves more than simply having a say, and should be understood as democratic involvement in the production and reproduction of everyday life (McMahon et al. 2018; Percy-Smith 2006). Such a formulation acknowledges participation as a direct form of knowledge production, learning and action in situated social contexts (Lave and Wenger 1991) as young people reflexively engage as autonomous, self-determining social actors and authors of their own lives. Whilst there is increasing awareness of the diversity of new democratic arenas that are serving to broaden and deepen democracy, however, less is known about how young people produce knowledge and action in different ways, in different contexts and for different purposes.

This paper responds to this gap by drawing upon a recently completed international study to provide insights into the different ways in which young people construct knowledge and action as they seek to participate in the context of their everyday lives and concerns and in a struggle for recognition within democratic societies.

\section{Youth-led action research: exploring knowledge democracy in action}

The research study started from the position that young people are participating, but not necessarily in ways that a political elite recognise as participation. Working in eight European cities (Frankfurt, Rennes, Manchester, Gothenburg, Bologna, Zurich, Plovdiv and Eskişehir), the research aimed to explore how and where young people aged 15-30 participate. Following an initial phase of policy and literature analysis, a second phase of ethnographic case studies explored young people's political, social and civic participation across formal (e.g. youth councils), non-formal (e.g. third sector) and informal (e.g. activist groups) spaces.

The third phase involved youth-led action research projects, on which the current paper is based. The aim of this phase was to provide a space for young people to make sense of participation in action through their own lenses of meaning, by supporting them to undertake their own projects on issues and questions that they identified as important to them. The groups of young people devised and led the action research projects, facilitated and supported by the national research teams. (Most of the groups had already been involved in the earlier ethnographic phase of research, but a few were new.) The projects took shape through discussions of ideas and possibilities with the young people and were developed according to the young people's visions for learning and outcomes. The researchers provided ongoing support in regular reflective meetings with young people as well as training and resources (including a sum of money to be used as the group chose).

There were 18 action research projects across the eight cities. The aims varied, from projects working for inclusion and justice for group members, to projects which aimed to articulate group 
values and identities, to projects seeking solutions to social problems, and to projects which aimed to activate and engage peers by tackling barriers to participation.

Action research is frequently understood as a process of 'learning for change' (McTaggart, Nixon, and Kemmis 2018) involving critically reflective inquiry (Wadsworth 2011; Weil 1998) and engaging with living theories of action (Whitehead 2018). Carr and Kemmis $(1986,162)$ state that 'action research is simply a form of self-reflective inquiry undertaken by participants in social situations in order to improve [...] their own practices, their understanding of these practices and the situations in which the practice are carried out'. For Weil (1998), action research involves challenging taken for granted assumptions as a basis for developing alternative understandings and practices through cycles of learning, action and reflection, in dialogic spaces of shared meaning (Rowell, Riel, and Polush 2018). In this way, Cammarota and Fine $(2008,4)$, drawing on Freire's praxis of critical reflection and action, refer to Youth Participatory Action Research (YPAR) as a 'formal pedagogy of resistance' involving 'young people critically reflecting on their contexts, engaging in critical research, and collectively challenging and resisting forces impeding possibilities of liberation'. This approach to research implies deliberately destabilising traditional research approaches in order for young people to challenge and reanimate dominant discourses of participation. YPAR, therefore, provides 'a way of redefining knowledge as actions in pursuit of social justice' (Cammarota and Fine $2008,6)$. This echoes Rowell and Long's (2018) assertion that research must respect the knowledge of the people in action research processes.

As researchers commissioned by the EU to generate new knowledge about youth participation within limited timescales and with project deliverables, this phase aimed to engage young people in reflecting critically on their own participation experiences and knowledge through developing projects around their needs and interests and learning from that experience. The projects were not prescribed in terms of process because of the emergent and contextually specific nature of action research. Instead, the national research teams and the groups of young people were encouraged to approach the projects as they saw fit. Most projects adopted a quasi-form of action research, which at least involved young people taking action and learning from their experiences. The young people undertook data collection, analysis and interpretation in a variety of ways according to the nature of the projects.

Of the 18 projects, some followed a traditional research process (e.g. young people undertaking interviews and analysing responses), others took a more action-focused approach (e.g. community activities such as migrant groups cooking food in the com-munity to encourage social interaction with the host community), while others made a creative output (e.g. a play) as a way of exploring and articulating how they were making sense of their situation. All 18 projects produced video material and self-documentation in some form (e.g. written notes and commentary), as this was a deliverable tied to the EU funding. In addition, all 18 projects included ongoing discussions with national teams meeting with the young people to reflect on their projects, the significance of what they had done and what they had learned about different forms of participation.

Following the work with young people, national research teams undertook an analysis and sensemaking of their city's projects in order to produce the project reports. A final level of analysis involved national research teams reflecting on learning across all of the different projects, and a core group (including the authors of this paper) pulling together what had been learned across the eight cities. The current paper draws upon this synthesis, the individual country reports, and young people's and national researchers' reflections.

This paper draws upon the experiences in three of the projects in order to illustrate the diverse ways in which action research with young people can bring about new forms of knowledge democracy in formal, non-formal and informal spaces. These examples highlight the ways in which young people 
produced, communicated and acted upon knowledge as they struggled for recognition, respect and social justice, sought to give meaning to their own values and identities, and actively contributed as citizens.

These three projects had very different aims: the first explored and presented the knowledge and lived experiences of young people seeking asylum in a search for recognition and rights; the second aimed to understand political 'apathy' among young people; and the third looked for ways to express a particular youth (sub)culture in the public realm. In terms of knowledge, the first drew mainly and strongly on existing knowledge and experience within the group, the second drew on the group's own knowledge and experience but also sought new knowledge explicitly through research, and the third predominantly explored a new way of creating knowledge and learning through practice. In what follows, all identifying details have been changed.

\section{'Faceless': young people communicating struggles for justice through public dialogue}

The first project was with young people attached to a charity organisation (a non-formal group) that supports people seeking asylum in the UK and campaigns around human rights and asylum. The work with this group began with a brief scoping activity with a small group of young members comprising five 17- to 28-year olds, three women and two men, from Congo and Pakistan. The young people who made up the group had come to the organisation to seek support in some form (e.g. support for asylum applications) and to make contact with other people seeking asylum.

After the researcher explained the purpose of the wider project to the young people, they were invited to develop ideas for a project about 'participation' rooted in their lived experience. They began by exploring the meaning of participation to them and in particular, the barriers to participation they experienced because of their lack of refugee status. All of the young people were engaged in personal and legal struggles to establish a right to remain in the UK and were either in the process of making a case for asylum (to the Home Office) or were completely 'undocumented' (i. e. they did not have a current asylum application). From the outset, the young people were clear in their aim to create a dialogue with the public about the lived experiences of being a young person seeking asylum in a 'hostile environment'. After a few sessions, the group members invited others to join the research group and the group grew in number to 10 - five young women and five young men, with new members from Trinidad \& Tobago and Rwanda. Four of the young people were siblings. Working together in weekly sessions over two months, the 10 members developed a variety of ideas for how to generate dialogue, and eventually divided into two smaller groups. One group of six young people produced short essays on the issues which affect asylum seekers' participation (such as lack of access to higher education) and discussed how to use their work for public dialogue. The other group decided to write and perform a play to depict their lived realities of seeking asylum. The work of the drama group (three young women and one young man) is the focus of the remainder of the case study.

The play that the group produced, 'Faceless', written by one young person and performed by three others, explored the invisibility of the asylum seeker and featured two 'faceless' people and their interaction with a 'stranger'. After rehearsing the play together in various locations in the city, and amending the script to include ideas from the group, the young people filmed and then produced a final version of the play.

Reflecting on the work, the young people noted that they found it rewarding, personally and collectively, to be part of a project that could speak to the public about their lived realities. Through it, they found belonging, emancipation, citizenship, and, despite a consistent and often unspoken sense of their legal and social precarity, an undeniable sense of fighting back (against a 'hostile environment') and fighting on (for their rights). The project, therefore, became a form of active citizenship and activism for the young people, and the aim of showing their lives to the public was 
always at the forefront of their minds. In order to do this, the young people drew from their experiential knowledge of their lives as young people seeking asylum, their experiences of the asylum system and of being part of a maligned, marginalised and invisible group.

A striking feature of the Faceless group was how they worked together to create the play and to agree on the experiences that they wanted to depict. The play was, initially, the work of one young person who also 'directed' the play and its filming. As the project progressed, however, all members of the group contributed to its development. The script, acting, and filming location were decided democratically between the members, and they also met outside of the scheduled sessions to work on the play together.

Reflecting on how they worked together, the young people noted that they were committed to ensuring that they jointly owned and developed the work. As a newly formed group, the young members utilised their knowledge and talents, and shared their understandings, in egalitarian ways in order to ensure that the experiences that Faceless depicted were relevant to each of their lives.

At the time of writing, the young people in this group were continuing to working with the researcher on activist campaigns, awareness-raising and civic action, by using and developing their experiential knowledge of the asylum process.

\section{The Party Youth Section: responding to political apathy}

While Faceless was primarily concerned with the ways in which experiential or group knowledge permeated the young people's action research project, the second project set out explicitly to generate new knowledge about youth political apathy in Bulgaria. The Party Youth Section (PYS), a formal group, was established in 2009 within all major city structures of the Party, and is subordinated to the national party leadership. At local level, the PYS has considerable freedom in devising and carrying out initiatives. The PYS in Plovdiv included 35 members who were largely lower middle-class, mostly women, and aged between 25 and 27 . Unlike the Faceless group, the young people in the PYS had worked together for a long time. They all shared a political ideology and were politically active in the city. They were chosen to be part of an action research project because of the young people's consistent functioning over years, experience in project and campaigning work, and experience of analysing findings.

In terms of project focus, the group were interested in exploring youth political 'apathy' and a perceived de-politicising of young people, during a period of political instability with numerous changes of government and allegations of corruption and lack of accountability, and because they, as political actors themselves, felt unable to affect change. The group decided to conduct research interviews and focus groups with their peers in the city, in order to understand young people's: (1) motivations, or lack of, for voting activity in elections; (2) interest in politics and current affairs more generally; (3) attitudes to politics and politicians; and (4) views on the emigration of young people from Bulgaria. The group thus aimed to generate knowledge as a basis for under-standing and then activating youth political engagement.

Through speaking with other young people in the city, the group learned that young people in Bulgaria have negative views of formal politics and a distrust in political institutions. At the same time, the young people who responded had a sense of optimism about the future and remained committed, in some form, to Bulgaria's development. The PYS concluded that young people in Bulgaria lacked motivation to con-tribute to the country's future, per se, and they were particularly concerned about increasing depopulation within younger generations, as young people were seemingly seeing more attractive futures elsewhere. The motivation behind this work therefore was to engage with young people and, through understanding better their situation, try to enable them to feel a greater sense of empowerment both politically and in terms of future work prospects. 
Whereas other groups were concerned with learning how to work together, the PYS had worked together for some time around a shared agenda and, through dialogue, were able to progress more easily to action. From their learning from the action research, they formulated three actions for their ongoing work: (1) to understand and challenge depopulation in younger generations; (2) to increase youth empowerment, particularly in formal politics; and (3) to improve transition to work by involving universities to support the professional needs of graduates. This work is ongoing and is focused on working on the actions for change.

\section{'Hoodboys': young people performing knowledge through action}

An implicit assumption of participation is that people engage in some kind of decision-making and change process with a view to deriving some kind of benefit from the outcomes. Yet democracy is also about having the freedom to express who you are through cultural values and actions. Inclusion within a democracy is therefore also about self-determined action and expression, for example, in terms of subcultural styles. The third action research project in this paper focused on young people's democratic participation in terms of how and where they used public space through street art. Esoteric knowledge underpins these forms of democratic action, with meanings particular to these groups expressed and communicated in particular ways. For these young people, there was an ambivalence in their positioning. On the one hand, they were forming identity through articulating cultural difference reflected in territorial demarcation and an explicit distancing from the 'mainstream'. On the other, they were in some ways seeking acknowledgement and recognition for their difference. This negotiation of difference involved navigating stereotypes, anxieties and expectations around social norms and normativity. These young people did not want to conform, but they still sought acceptance and recognition by communicating knowledge through action and raising awareness.

The 'Hoodboys' project involved an informal 'crew' of young graffiti artists in their 20s in Frankfurt, consisting of eight core members and two 'prospects' or newcomers. Most of the members had had a long-standing interest in graffiti, and they had experience of both legal and illegal painting. Work or studies (arts, architecture, social sciences and design) occupied all of the members.

The graffiti painting scene represented a parallel world in which the young people felt in control, and where they could create and express in ways that could achieve recognition both from other graffiti crews and from the public. Originally, the crew was a subcultural formation that found spaces in the public that they could use for graffiti, and the group was still involved in these activities. Over time, however, as their skills developed, some of the group had become more and more occupied in transferring their competencies into commercial arenas, which pay them for their artistic work. The aim of the action research project was to create a graffiti event ( $\mathrm{a}$ 'jam') and to document their work in the jam in order to reach out to the public about graffiti culture and what it could mean for individuals and groups to be a part of it. In doing so, the group wanted to communicate a new understanding of graffiti culture in terms of how it illustrated the artists' belonging within a cityscape, their reclamation of city space for art and expression, their identity work through spraying in public spaces, and their commitment to graffiti as a legitimate art form and mode of participation. This project was arguably unusual in terms of action research. Nonetheless, in the coming together of reflection (ongoing dialogue between the group members and the national researchers) and action (creating the video and narrative) with the purpose of generating new knowledge, the young people developed, illustrated, and made sense of a form of participation through action.

The young people chose a video as the communication tool to give to interested parties, including service providers, and the wider public. In doing the action research project, the Hoodboys and national research team went through four stages: (1) setting up the project by getting equipment (spray cans, a recording device) and deciding upon the project aims through discussion; (2) doing the jam and recording the footage; (3) creating an accompanying narrative for the video footage to 
articulate the group's graffiti work, their identities around their art, and their use of public space in the city; and (4) a presentation of the video to the national research team followed by a discussion between the group and the national researchers.

The project illustrated how the group performs personal and social identity through the collective action of a youth group. Group reflections, and the video of the jam, returned frequently to the importance of maintaining a distinct group identity, regard-less of some members of the group becoming more involved in legal artistic activities. Crucially, the action research was about showcasing and celebrating the group's collective energies and their knowledge of graffiti art, and using space to interact with the public about the meaning of their art and its place in the cityscape.

The ways in which the members of Hoodboys worked together in the project contrasted again with the other projects presented in this paper. The Hoodboys were long-established and the members were part of a close-knit community. Observing the work of the young people as they 'sprayed', the researcher remarked upon their instinctive 'flow' with each other and how they moved around the space, picking up a part of the work where another had left off. The artwork itself came from their shared practice of graffiti, and vision for their group, which was also long-standing. Like the PYS, and in contrast to the newly formed Faceless group, the process of the Hoodboys working together was often unspoken as they engaged in tacit knowledge exchange through embodied meaning in action.

\section{Knowledge democracy and the promise of action research}

Knowledge democracy took a number of forms in these projects. By sharing their experiences in a dramaturgical form, the young people in Faceless engaged in a 'knowledge democracy' in two main ways. First, they undertook the process of exploring and sharing their common experiential knowledge on a basis of equality. The young people retained ownership throughout the project; the 'professional' researcher supported the work on the basis that the key knowledge and initiative rested with the young people. Second, a starting motivation for the project was that it would contribute in some way to the young people's struggle to be recognised and accepted as members of the community with rights and a valuable contribution to make. This engagement with processes of activism and change suggests that Faceless was seeking to interrupt, and then challenge, dominant perspectives (and, indeed, knowledge) through its knowledge production. Together, these two points reflect the two dimensions of the relationship between knowledge and democracy outlined above. First, that knowledge democracy involves different forms of expression and articulation of values, views and meanings. The power in the work of the young people in the Faceless project was to explore and communicate a deeper sense of their lived realities and the ways in which bureaucratic systems and processes limit the realisation of their fundamental human rights. Second, that through these different forms of knowledge production, young people were better able to contribute to wider democratic processes in ways that are more meaningful and (potentially) impactful.

The graffiti artists shared their experiential knowledge through the action research project by creating an artwork depicting the unique style of graffiti that spoke directly to their identity, while at the same time seeking public recognition of graffiti as a legitimate art form. In this case, recognition was concerned with young people's place and space within a city that was unaccepting, and even hostile, of their activity. For young people in both the Faceless and the Hoodboys case studies, knowledge democracy and action was dynamic and co-produced actively through their (sub)cultural activity, as a way of taking action with the purpose of bringing about social, cultural and political change. In addition, the Hoodboys action research project was a reciprocal process which produced different knowledge by and between everyone involved; while the professional researcher gained knowledge about the young people and their activities and culture, the young people learned in an informal way about the researcher's world. This was particularly important to those members of the 
group who were becoming interested in legal forms of spraying, who enjoyed being in a university environment and learning about research.

The PYS project was explicitly concerned with generating knowledge to support democratic structures and practices that can empower young people to take more active roles in contributing to social futures and hence involved conceiving of knowledge as a 'powerful tool for taking action to deepen democracy' (Hall 2013, 7). However, the group here too utilised the experiential knowledge of young people living in Bulgaria in order to generate ways to address democratic deficits, rather than seeking to mobilise their engagement in pre-existing structures and processes from which they already felt marginalised.

There are recurring strands across the examples that highlight the ways in which youth participation can allow young people to generate, communicate and act on knowledge as a democratic process. First, because of learning in action, young people are able to build their own capacity for democratic participation, by developing skills and confidence, increasing awareness of their own agency in relation to wider society and, through experiential learning, opening up new possibilities for action. The PYS's concern was not just about exploring young people's views and attitudes, but was also about responding to perceived political apathy by raising young people's awareness and encouraging youth engagement. Carr and Kemmis (1986) refer to this as 'becoming critical' - empowering young people to participate by developing a political conscious-ness. Rather than deferring to established mainstream democratic structures that can limit possibilities for participation, then, young people through action have more control over the ways in which they democratically engage.

Second, as the experience of the PYS illustrates, through engaging in self-determining action on their own terms, young people are championing the issues and priorities that are most relevant to their immediate situations, rather than responding to a third party agenda. Similarly, the Hoodboys and Faceless developed action based on values and interests originating in lived realities. By cohering around shared concerns, young people develop a sense of identity with others and, in so doing, nurture a sense of solidarity as well as sociality as they participate.

Third, the growing trend towards 'informal' participation in everyday contexts amounts to the activation of situated knowledges, such that 'socially situated' interests, proposals, claims, and expressions of experience become an important resource for democratic discussion and decisionmaking. Such situated knowledges can both 'pluralize and relativize hegemonic discourses, and offer otherwise unspoken knowledge to contribute to wise decisions' (Young 2000, 7). Wildemeersch et al. (1998) refer to this as participatory social learning wherein the emphasis is on the 'optimal use that should be made of the problem-solving potential of a group, a network, an institution or a community' (252, emphasis in original). Social learning in these terms is action- and experience-oriented. It is also critically reflective, which means that actors question the validity of particular opinions, judgments, strategies, actions, emotions, and feelings. And it is cooperative and communicative and dialogue between actors is crucial as actors are continually involved in implicit or explicit processes of negotiation (Wildemeersch et al. 1998).

Fourth, broadening the epistemological and ontological scope of democratic activity and 'legitimate' forms of knowledge (as takes place in 'new democratic arenas') enables young people to more readily exercise freedom to articulate their values and experiences using different ways of knowing in a wider range of ways. Action research in turn offers a methodological approach to enable the expression of, and engagement with, different forms of knowing and therefore with the authenticity of human experience. Key to the projects explored in this paper was the ways in which young people's reflections helped them to understand and articulate their situation better, in order to try to open up possibilities for action. In the Faceless project, this was clearly reflected in a realisation 
that active citizenship, and indeed the process of becoming an active citizen, involved different forms of participation:

The young people were acutely aware of ways in which they cannot participate - they cannot work and they cannot access higher education ('Universities do not take people like

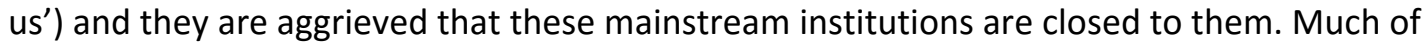
the discussion in the scoping project was about the about the ways in which all of the young people feel insecure and vulnerable because of their status: 'the uncertainty is like floating on the water [...] we might get rescued but it is a waiting game'. On the one hand, they feel constrained by their status: '[I'm in] prison, I can't do so many activities that I want to do. Still hanging around, I can't do anything, I'm helpless'. On the other hand, they are not sure of 'what [they] would participate in'. They know that participation is dependent on 'being listened to, being accepted, being treated equally' and they feel that they are not accepted or respected because they are people seeking asylum: 'A lot of people think they are higher status, hierarchy, you are an asylum seeker and I am not'. (Extract from national report based on field notes)

Faced with such limited possibilities for legitimate participation, the young people explored new forms of democratic participation. In the space that the action research projects provided, young people engaged in multifarious forms of creative expression such as drama, video, art installations, music and graffiti to convey a deeper sense of who they are and their experiential realities. In parallel to focusing on new democratic arenas, there is therefore also value in considering alternative forms of 'inclusive communication' (Young 2000). The value in creative forms of expression, however, lies not only in providing a preferential style of participation but also, through revealing a deeper knowing in the form of the experiential roots of values, priorities or cultural meanings, can go some way to providing the shared premise for democratic discussion that Young (2000) highlights as imperative.

Fifth, by offering a space in which young people could identify their own objectives and choose their own methods of working, the projects provided insights into the ways in which young people organise, relate to each other, learn, and make decisions.

In my country we say, one finger can't wash the face, if it is all five, we can wash the face. When the people are together, one two three four five, in the group, we can make change, we can bring our personality and our thoughts [and our consciousness]. If people participate with me, five or ten. . .we can make change. (Extract from one young woman in field notes)

A clear ethos of joint endeavour, cooperation, commitment and respect for each other and the imperative of valuing different contributions was notable; whether that be the commitment of the young people in Faceless to ensuring that they jointly owned and developed the work, or the 'instinctive flow' with which the Hoodboys worked with each other. In addition, an ethos of democracy, fairness and respect, as young people worked with issues of social justice and rights, underpinned each of the projects. The ways that young people worked together as groups further reflected these principles and illustrated young people's commitment to responsibility and collective processes in which all voices and contributions are valued. This embodiment of democratic principles solidified by a profound sense of social justice and rights illustrates a commitment to the promise of the democratic ideal that established structures and practices have neglected. To that extent, evidence suggests that there is much to be gained from understanding and valuing the contribution that 'youth', as a generative and creative phase of the life course, can make to new forms of knowledge democracy and, more widely, democratic renewal (Gaventa 2007). 
The action research projects clearly illustrate the ways in which knowledge democracy enables young people to express their democratic rights in a variety of ways. The extent to which the different forms of knowledge produced and shared had tangible impacts beyond the time and reach of the projects is less clear, however, and is linked to power and the young people's access to democratic structures and processes. In addition, the extent to which the young people believed that their action research projects were successful in terms of exercising their democratic voice, and having their voice heard, is also difficult to assess particularly in the short-term.

Undoubtedly, the young people seeking asylum and the young graffiti artists were proud of their creative products and they believed in the capacity of their creations to speak to the public. The young people in the PYS were satisfied that their project generated knowledge that they could use going forward. It is therefore plausible to speculate about the impact, or the potential impact, of some the projects within discourses of power. On the one hand, power in the context of knowledge democracy may be a way of seeking, promoting and recognising the influence that different groups and processes of participation have on the democratic process. Yet, in spite of the merits of selfinitiated action and arguments for recognition of the democratic action of different groups, beyond inherent benefits within these groups, the extent to which their democratic action brings about change remains dependent on the extent to which they are able to communicate and contest the broader social, economic and political forces that shape their lives. The evident preference of many young people for less formal forms of participation as lived practice, and for constructing their own attempts at remaking democracy in their own vision and according to their own needs, suggests that knowledge democracy within their localised everyday worlds is just as important for them as wider social change. Power in these terms is less about an influence on mainstream, decision-making politics as it is about individuals and groups as social actors exercising their own political agency in response to their priorities, interests and concerns. Consequently, evidence from this research suggests that knowledge democracy involves a plurality of forms of democratic engagement and political activity as well as diversity of representation in mainstream politics.

\section{Conclusion}

Using findings from recent research across Europe examining the styles and spaces of youth participation, this paper has explored the significance of young people's own choices for democratic knowledge production, communication and engagement within a context of shifting discourses of participation, democratic engagement and active citizenship. By freeing up thinking concerning normative assumptions about knowledge and democratic practice, new forms, understandings and practices of knowledge democracy can emerge that reflect the promise of inclusive democratic societies more meaningfully. The evidence from explorations of young people's preferred forms of participation using action research - involving use of creative forms, learning in action, as situated social practice in everyday contexts, as cooperative, and as fluid, emergent and reflexive processes of social engagement - contributes to growing discourses concerning (young) people's participation as well as new forms of knowledge democ-racy in 'new democratic arenas'.

\section{Acknowledgments}

The views and perspectives expressed in this paper are those of the authors. The European Commission are not responsible for any information in this paper. The authors would like to acknowledge the work of the research consortium in collectively generating a wealth of material from which this paper draws, as well as the young people who engaged with us in the action research projects.

\section{Disclosure statement}

No potential conflict of interest was reported by the authors. 
Funding

This paper is based on the Partispace research, funded by the European Commission under Horizon 2020 research and innovation programme under grant agreement no. 649416 .

\section{References}

Cammarota, J., and M. Fine. 2008. "Youth Participatory Action Research: A Pedagogy for Transformational Resistance." In Revolutionising Education: Youth Participatory Action Research in Motion, edited by J. Cammarota and M. Fine, 1-12. New York: Routledge.

Carr, W., and S. Kemmis. 1986. Becoming Critical: Education, Knowledge and Action Research. London: Routledge Falmer.

Cornwall, A., and V.S. Coelho, eds. 2007. Spaces for Change: The Politics of Citizen Participation in New Democratic Arenas. London: Zed Books.

Fals-Borda, O. 1998. People's Participation: Challenges Ahead. Rugby: ITDG Publishing.

Fielding, M., and P. Moss. 2011. Radical Education and the Common School: A Democratic Alternative. London: Routledge.

Gaventa, J. 2004. "Towards Participatory Governance; Assessing the Transformative Possibilities." In Participation: From Tyranny to Transformation? edited by S. Hickey and G. Mohan, 2541. London: Zed Books.

Gaventa, J. 2007. "Foreward." In Spaces for Change: The Politics of Citizen Participation in New Democratic Arenas, edited by A. Cornwall and V.S. Coelho, $\mathrm{x}$-xviii. London: Zed Books.

Hall, B. 2013. "Knowledege Democracy and Social Justice: Implications for Higher Education." Paper presented at the 100th Anniversary of the Association of the Commonwealth, London.

Henn, M., and N. Foard. 2012. "Young People, Political Participation and Trust in Britain." Parliamentary Affairs 65 (1): 47-67. doi:10.1093/pa/gsr046.

Hickey, S., and G. Mohan. 2004. Participation: From Tyranny to Transformation. London: Zed Books.

Lave, J., and E. Wenger. 1991. Situated Learning: Legitimate Peripheral Participation. Cambridge: Cambridge University Press.

Lister, R. 2008. “Unpacking Children's Citizenship." In Children and Citizenship, edited by A. Invernizzi and J. Williams, 9-19. London: Sage.

Matthews, H., M. Limb, and B. Percy-Smith. 1998. "Changing Worlds: The Microgeographies of Young Teenagers." Tijdschrift voor Economishe en Sociale Geografie 89 (2): 193-202. doi:10.1111/1467-9663.00018.

McMahon, G., B. Percy-Smith, N. Thomas, Z. Bečević, S. Liljeholm Hansson, and T. Forkby (2018). "Working Paper: Young People's Participation: Learning from Action Research in Eight European Cities." doi:10.5281/zenodo.1240227. 
McTaggart, R., R. Nixon, and S. Kemmis. 2018. "Critical Participatory Action Research." In The Palgrave International Handbook of Action Research, edited by L. Rowell, C. Bruce, J. Shosh, and M. Riel, 21-35. New York: Palgrave Macmillan.

Percy-Smith, B. 2006. "From Consultation to Social Learning in Community Participation with Young People." Children Youth and Environments 16 (2): 153-176.

Percy-Smith, B. 2018. "Participation as Learning for Change in Everyday Spaces: Enhancing Meaning and Effectiveness Using Action Research." In Theorising Childhood: Citizenship, Rights and Participation, edited by C. Baraldi and T.Cockburn, 159-186. New York: Palgrave Macmillan.

Phillips, A. 1993. Democracy and Difference. Cambridge: Polity Press.

Pickard, S., and J. Bessant. 2018. Young People Re-Generating Politics in Times of Crises. Basingstoke: Palgrave Macmillan.

Rainsford, E. 2014a "Political Parties Need to Better Integrate Young Members and Give Them the Chance to Influence

Policy." Accessed 23 August 2018. http://www.democraticaudit.com/2014/07/11/political-partiesneed-to-better-integrate-young-members-and-give-them-the-chance-to-influence-policy/

Rainsford, E. 2014b. "Young People and Political Parties." In Beyond the Youth Citizenship Commission: Young People and Politics, edited by A. Mycock and J. Tonge, 48-51. London: Political Studies Association.

Rowell, L., and E. Long. 2018. "Knowledge Democracy and Action Research: Pathways for the Twenty-first Century." In The Palgrave International Handbook of Action Research, edited by L. Rowell, C. Bruce, J. Shosh, and M. Riel, 63-83. New York: Palgrave Macmillan.

Rowell, L., M. Riel, and E. Polush. 2018. "Defining Action Research: on Dialogic Spaces for Constructing Shared Meanings." In The Palgrave International Handbook of Action Research, edited by L. Rowell, C. Bruce, J. Shosh, and M. Riel, 85-101. New York: Palgrave Macmillan.

Thomas, N. 2007. "Towards a Theory of Children's Participation." International Journal of Children's Rights 15 (2): 199-218. doi:10.1163/092755607X206489.

Wadsworth, Y. 2011. Building in Research and Evaluation: Human Inquiry for Living Systems. Hawthorn: Action Research Press.

Walther, A. 2018. "Re-Thinking Youth Participation - Contributions of PARTISPACE." http://partispace.eu/cms/wp-content/uploads/2018/06/PARTISPACE-Working-paperre-thinking-youth-participation.pdf

Weil, S. 1998. "Rhetorics and Realities in Public Service Organisations: Systemic Practice and Organisational Learning as Critically Reflexive Action Research." Systemic Practice and Action Research 11 (1): 37-62. doi:10.1023/A:1022912921692.

Whitehead, J. 2018. Living Theory Research as a Way of Life. Bath: Brown Dog Books. 
Wildemeersch, D., T. Jansen, J. Vandenbeele, and M. Jans. 1998. "Social Learning: A New Perspective on Learning in Participatory Systems." Studies in Continuing Education 20 (2): 251-265.

doi:10.1080/0158037980200210.

Young, I.M. 2000. Inclusion and Democracy. Oxford: Oxford University Press. 